\title{
Embalagem para perfume com referência em aspectos art déco da arquitetura de Rio Tinto
}

\author{
Perfume packaging with reference in art deco aspects of Rio Tinto's architecture
}

SANTOS, Juciely; Pós-graduanda em Design; Faculdade de Administração Ciências Educação e Letras

jucytargino@hotmail.com

LEHMKUHL, Luciene; Doutora; DDesign, Universidade Federal da Paraíba

lucilehmkuhl@hotmail.com

ACIOLY, Angélica; Doutora; DDesign, Universidade Federal da Paraíba

angelica@ccae.ufpb.br

\section{Resumo}

O presente artigo apresenta o desenvolvimento de embalagem com referência nos aspectos art déco da arquitetura da cidade de Rio Tinto, realizado na Universidade Federal da Paraíba, destinado ficticiamente à empresa Granado/Phebo, um cliente potencial. No embasamento teórico utilizou-se pesquisa bibliográfica, documental e de campo, foram abordados os temas art déco, Rio Tinto e embalagem, possibilitando a estruturação e desenvolvimento do projeto. Para dar suporte a fase de criatividade foram desenvolvidas séries de painéis visuais de caráter mutável alimentados ao longo da pesquisa. $O$ conceito foi escolhido por meio de análise comparativa tendo por norte critérios baseados nos requisitos e parâmetros do projeto. A paleta de cores utilizada foi obtida por meio de análise de cores presentes nos painéis visuais. O produto final é exclusivo e portador de configuração visual que remete à cidade de Rio Tinto e às características art déco de sua arquitetura.

Palavras Chave: art déco; embalagem; perfume e Rio Tinto.

\begin{abstract}
The present article presents the development of packaging with reference in the art deco aspects of the architecture of the city of Rio Tinto, realized at the Federal University of Paraiba, fictitious destined to the company Granado / Phebo, a potential client. In the theoretical basis was used bibliographical, documentary and field research, the subjects were approached art deco, Rio Tinto and packaging, making possible the structuring and development of the project. In order to support the creativity phase, we developed a series of mutable visual panels fed throughout the research. The concept was chosen through comparative analysis based on criteria based on the requirements and parameters of the project. The color palette used was obtained through the analysis of colors present in the visual panels. The final product is unique and has a visual configuration that reminds Rio Tinto and the art deco features of its architecture.
\end{abstract}

Keywords: art déco; packing; perfume and Rio Tinto. 


\section{Introdução}

O presente artigo objetiva apresentar o desenvolvimento de uma embalagem para perfumaria que tem como referência aspectos art decó presentes na arquitetura da cidade de Rio Tinto, Paraíba. Este projeto foi desenvolvido durante a elaboração do Trabalho de Conclusão de Curso e a temática que o norteou surgiu do interesse suscitado pelas características estilísticas da arquitetura da cidade fábrica de Rio Tinto, cuja edificação se deu entre meados de 1920 e final de 1940. Durante pesquisas preliminares, verificou-se que a empresa Granado/Phebo possui forte ligação com o art decó, havendo na marca toda uma linha com embalagens nesse viés, então a definimos como empresa alvo, para a qual foi desenvolvido o produto.

Foi observado em pesquisas iniciais que o setor de design de embalagem é bastante expressivo no Brasil, bem como o setor de Higiene Pessoal Perfumaria e Cosméticos, viu-se então a oportunidade de investir nesses setores, por meio do projeto de embalagem para perfume. 0 design como atividade projetual se vale das mais diversas fontes de inspiração para a conceituação de produtos, seja ela um povo, um costume, a arquitetura ou ainda um fazer artesanal. Escolhemos a arquitetura da cidade Rio Tinto como fonte de subsídios para projetação.

Objetivando fornecer conhecimento para solucionar a problemática abordada pela pesquisa foram utilizadas ferramentas de pesquisa documental, pesquisa bibliográfica, levantamento de dados, pesquisa descritiva e pesquisa de campo, com intuito de se conhecer o movimento art decó, a arquitetura de Rio Tinto, embalagens para perfume e produtos com o viés art decó. Para a projetação optamos por usar o Guia de Orientação para o Desenvolvimento de Embalagens (GODE) (MERINO et al. 2009) por acreditarmos que os momentos propostos no Guia possibilitaram o adequado desenvolvimento do projeto.

\section{Desenvolvimento}

\subsection{Metodologia}

Para realizar o processo de projetação foi utilizado como metodologia o Guia de Orientação de Desenvolvimento de Embalagens (GODE) proposto por MERINO et al. (2009), que possui cinco etapas retroalimentadas e enumeradas de 0 a 4, desenvolvido no Núcleo de gestão de design da Universidade Federal de Santa Catarina. Vale ressaltar que, por esta pesquisa ter sido realizada no meio acadêmico, e pelo fato do método possuir características mercadológicas, foram feitas adaptações necessárias para uma melhor adequação a um trabalho de conclusão de curso, sendo ainda acrescidas ferramentas não sugeridas no método que foram de grande utilidade para a continuidade do projeto.

\subsection{Embasamento Teórico}

\subsubsection{Art déco}

$\mathrm{O}$ art déco foi um movimento de arte, artes aplicadas, design e arquitetura, de caráter internacional surgido na França na década de 1920, que teve seu auge no ano de 1925 com a Exposition Internationale des Arts Décoratifs et Industriels Modernes, realizada em Paris entre abril e outubro, que contou com 15 milhões de visitantes e cem pavilhões nacionais e estrangeiros. A exposição de 1925 foi uma iniciativa patrocinada pelo governo, concebida ainda em 1907 com o proposito de encorajar a cooperação e colaboração entre artistas, artesãos e 
fabricantes de manufaturas e de promover a abertura de mercados exportadores para as artes aplicadas francesas. (DEMPSEY, 2010, p.135). A expressão "art decó" surgiu da abreviação de Art Décoratifs (artes decorativas) essa abreviação apareceu pela primeira vez no livro de Armand Lanoux Paris 1925, e contou com a aprovação do governo francês. (ROITER, 2012, p.222).

O Art déco surgiu como um estilo elitizado, luxuoso, profusamente decorado, expressava o fascínio pelas inovações tecnológicas, sendo estas uma ambição comum, expressa como: velocidade, aerodinâmica, viagens, luxo, modernidade e lazer. Alguns movimentos artísticos causaram impactos e o influenciaram, tais como: fauvismo, cubismo, futurismo e o impressionismo, cujas características podem ser observadas por meio das linhas, formas e cores. Sofreu influências externas não restritas ao campo artístico, como a descoberta da tumba de Tutancâmon, que marcou o início do uso de referências egípcias, cores metálicas e, ainda a cultura do Jazz americano. É importante ressaltar que o art déco não se limitou apenas ao design ou arquitetura, mas estendeu-se à moda, pintura, escultura, música, dança, escrita e à ilustração com profissionais de destaque em cada uma das áreas.

No Brasil o estilo ganhou influências da cultura local, do tropicalismo e das raízes indígenas. As influências da cultura brasileira levaram ao art déco Marajoara que unia os ornamentos geométricos com os desenhos de nativos da ilha de Marajó, no Pará. A cultura marajoara foi ricamente explorada, devido às marcantes características culturais e aos diversos artefatos précabralianos encontrados na ilha. Ainda hoje o art déco é admirado e estudado ao redor do mundo, há inclusive um congresso Mundial denominado "World Congresses on Art Déco ${ }^{\circledR}$, que acontece bienalmente desde 1991, no qual pesquisadores, admiradores, estudiosos, especialistas e colecionadores vindos de diversas partes do mundo se reúnem para prestigiar o art déco. (ROITER, 2011, p.225).

\subsubsection{Rio Tinto}

Município paraibano, dono de uma arquitetura ímpar, distante $50 \mathrm{~km}$ da capital do estado, Rio Tinto, cidade-fabrica, tem sua história e fundação mescladas com as da Companhia de Tecidos Rio Tinto. Fundada pela família sueca Lundgren, em 1918. (PANET et al., 2002, p.67). Os Lundgren já instalados na cidade de Paulista, Pernambuco, buscavam expandir seus negócios, e para tal visavam terras baratas de preferencia rurais, com fontes de energia acessíveis e distantes da influencia de poderes como Estado, igreja e sindicatos, a fim de "superar dificuldades de atração e retenção de mão-de-obra pela indústria e ainda possibilitar uma ingerência direta [...] no cotidiano operário." (PANET et al., 2002, p.13). A cidade de Paulista possui características semelhantes a Rio Tinto, em especial na arquitetura, em decorrência do uso de tijolos aparentes. Ainda é possível citar exemplos de construções mundiais que seguem o mesmo estilo, como as edificações encontradas em Paris, que possuem tijolos aparentes usados como ornamento.

Estas edificações apresentam elementos ornamentais semelhantes aqueles encontrados nas edificações da cidade-fábrica de Rio Tinto, com tijolos assentados em diferentes posições, criando padrões ornamentais no próprio plano da parede, em relevos e vazados. (LEHMKUHL; DA SILVA. 2016, p.10)

O núcleo fabril instalado na cidade de Rio Tinto se destaca por sua organização e tamanho. Possui estrutura complexa dividida de acordo com classes sociais e trabalhistas. As edificações de uso coletivo como a igreja, cineteatro, tênis clube, escola e etc., são destaque, todas construídas em tijolos aparentes na tonalidade vermelha - fabricados pela Olaria Rio Tinto primeiro empreendimento dos Lundgren na cidade - e possuíam influência europeia, "principalmente 
inglesa" no estilo Manchesteriano, com elementos decorativos característicos do art déco. O tijolo era usado como material nobre que diferenciava e acentuava a importância das edificações. (PANET et al., 2002, p.40 a 60).

Os elementos art déco na arquitetura se caracterizam pela geometrização das formas e de elementos decorativos, elementos abstratos, alusão à aerodinâmica, hierarquizações expressas em escalonamentos, na ênfase dada à entrada principal, e temas inspirados em culturas antigas como a Egípcia, Asteca, Grega. (PANET et al., 2002, p.50). É possível observar elementos art déco presentes na arquitetura de Rio Tinto, em especial em edifícios públicos, a Figura 1 destaca cineteatro Orion, no qual se pode observar com clareza elementos como: escalonamento, colunas em relevo, elementos decorativos em tijolo aparente, geometrização de planos formando composição geométrica em alto relevo e ainda o frontão que reúne todas essas características. "O tijolo aparente é elemento principal das colunas e paredes, compondo a fachada com destaque aos volumes e aos elementos em repetições." (LEHMKUHL; DA SILVA. 2016 p.7).

Figura 1- Cineteatro Orion

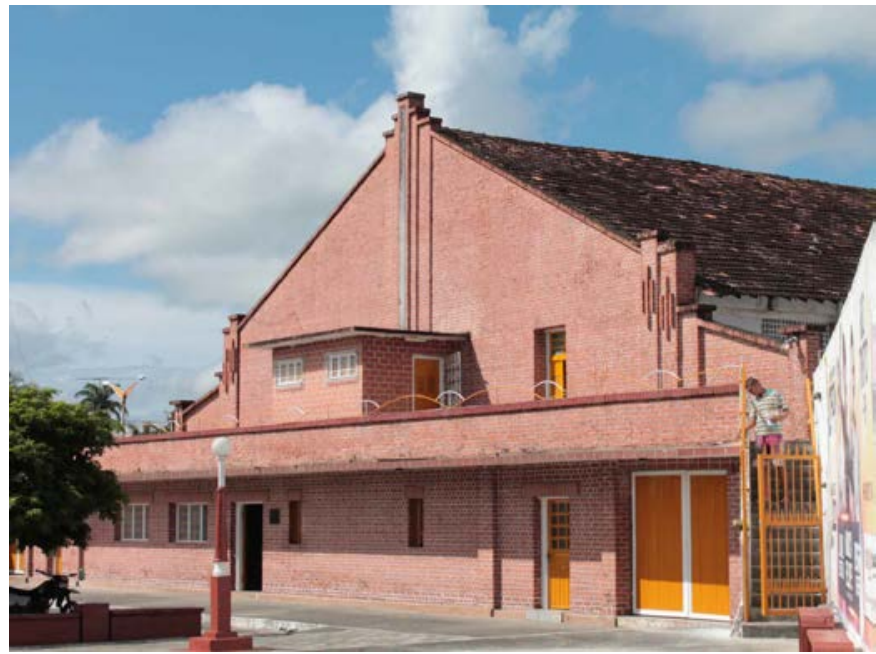

Fonte: LEHMKUHL; DA SILVA (2016). Acervo: Laboratório de Fotografia/Ddesign/UFPB

\subsubsection{Design de embalagens}

O uso de embalagem acompanha os primórdios da humanidade, desde que o homem viu a necessidade de proteger o alimento embalando-o, utilizando-se do material disponível para envolvê-lo e consumi-lo posteriormente. Negrão e Camargo (2008, p.23) declaram que: “[...] a embalagem tem sua origem antropológica e sociológica nos primórdios da civilização humana, pois se deriva da necessidade básica do ser humano de se alimentar e buscar formas de guardar e conservar seu alimento.". Está presente no cotidiano do ser humano servindo às necessidades de armazenar, preservar, conservar, transportar, e vem se aprimorando cada vez mais. O crescimento das cidades, a revolução industrial acompanhada por diversos fatores como o crescimento no número de pessoas assalariadas, e a massificação da produção de bens de consumo, provocou aumento no uso das embalagens. A distância cada vez maior entre a zona rural e a urbana evidenciou a necessidade diária de transportar alimentos em maiores distancias, revelando a necessidade de embalagens cada vez mais resistentes. (MESTRINER, 2002, p.3). 
As ornamentações das embalagens segundo Negrão e Camargo (2008, p.26) “[...] estavam estritamente ligadas a movimentos artísticos e seus rótulos refletiam essas referências visuais [...] movimentos como o art nouveu e o art déco." Assim, identificamos que os movimentos artísticos influenciaram o mercado de embalagens, desde seu primórdio, configurando-se como aspecto de interesse privilegiado para o desenvolvimento de embalagens.

\subsection{Desenvolvimento do Projeto}

Com o objetivo de verificar o mercado ou setor, levando em consideração o panorama nacional e internacional que a solução gerada buscou atingir, foram coletadas informações preliminares que são necessárias à confecção do Briefing. Foram realizadas visitas a web sites buscando-se embalagens art déco, buscas no Instituto Nacional de Propriedade Industrial (INPI), com intuito de verificar a existência de patentes nacionais, as palavras chave buscadas foram: embalagem perfume, frasco perfume, frasco perfume arquitetura, frasco art déco, embalagem art déco e art déco. Os resultados estão descritos na Tabela 1. Verificamos que há alguns depósitos de embalagem para perfume e o número aumentou consideravelmente quando usamos o termo "frasco perfume". Todavia, quando se buscou com termos art déco e relacionando este com embalagem não foram encontrados nenhuma patente ou desenho industrial.

Tabela 1 - Resultados das buscas por Patentes e Desenhos industriais no INPI

\begin{tabular}{lll}
\hline Palavra chave & Número de Patentes & Número de desenhos industriais \\
\hline Embalagem perfume & 9 & 6 \\
Frasco perfume & 57 & 108 \\
Frasco perfume arquitetura & 0 & 0 \\
Frasco art déco & 0 & 0 \\
Embalagem art déco & 0 & 0 \\
Art déco & 0 & 0 \\
\hline
\end{tabular}

Fonte: Santos (2017)

Foi Realizada por meio de pesquisa bibliográfica, em repositórios online como o portal da Capes, Google Acadêmico e Scielo, para a verificação do estado da arte no que diz respeito a pesquisas sobre a arquitetura da cidade de Rio Tinto, o art déco e embalagens, em especial para perfumaria. Foram pesquisados, de maneira física e digital, produtos inspirados nessa temática. Foram encontrados alguns produtos inspirados na arquitetura de Rio Tinto e diversos produtos inspirados no art decó em diferentes áreas do design, como no design de superfície, design de moda, design de joias e design de embalagens.

Realizou-se uma pesquisa de campo por meio de um formulário eletrônico a fim de conhecer quais aspectos relacionados a perfumes são mais importantes para os consumidores e quais aspectos traduzem qualidade, objetivando aplicar esses conceitos ao projeto do produto. Foram contabilizados cento e trinta e sete participantes, sendo $66 \%$ mulheres e $44 \%$ homens e a idade dos participantes apresentou variação entre quinze e cinquenta e nove anos. A maioria dos participantes $(33,6 \%)$ possui renda mensal de até um salário mínimo. Com relação aos aspectos 
que traduzem qualidade verificou-se que a maioria, $72 \%$ dos participantes, faz ligação entre qualidade e fragrância, o segundo aspecto mais apontado na pesquisa foi a durabilidade (fixação no corpo) que representou $67,4 \%$. Nos quesitos marca e embalagem (empatados como os menos votados com $21,7 \%$ ) houve pouca expressão ficando atrás até mesmo do preço, apontado por $27,5 \%$ dos participantes como um aspecto. Vale ressaltar que esta foi uma pergunta de múltipla escolha, na qual, se podia escolher simultaneamente mais de uma opção.

Sobre os tipos de perfume preferidos, obteve-se que a maioria, 43,5\%, prefere Parfum, em seguida aparece a categoria Eau de Parfum com 35,5 \% dos votos. O tipo de perfume que apresentou menor expressão de votos foi a Eau de Toilett. Esses dados que demonstram a durabilidade do perfume parecem ser muito importantes para o consumidor, haja vista que, os tipos de perfume que obtiveram maior expressão nesse tópico foram justamente os que têm maior fixação. Foi questionado ainda, o valor monetário em reais que os participantes estavam dispostos a pagar num bom perfume, obteve-se que a maioria, cinquenta e um participantes, estava disposta a pagar algo entre $R \$ 50,00$ e $R \$ 100,00$. Verificou-se com essa pesquisa que apesar de a maioria declarar preferência por parfum a maioria não estava disposta a pagar mais de cem reais num bom perfume.

As informações das etapas 0 e 1 do GODE alimentaram o Briefing do projeto:

- Oportunidade - foi identificada a partir da observação do setor de embalagem no qual foi percebido que este é um setor bastante expressivo na econômica brasileira; e ainda que o Brasil é segundo a Forbes Brasil (2014), o maior consumidor de perfume do mundo.

- Objetivo - desenvolver embalagem para perfumaria inspirada nas características Arte déco da arquitetura de Rio Tinto.

- Público alvo - mulheres adultas, com idade a partir dos 20 (vinte) anos, de classe média e média alta que possuam interesse por artes em geral, que conheçam ou demonstrem interesse específico pelo movimento/estilo art déco e que se identifiquem com a qualidade e tradição da Granado Phebo.

- Materiais - deverão seguir o padrão da empresa Granado Phebo, tanto na embalagem primária quanto na secundária.

\subsubsection{Analise e interpretação de dados}

Checklist de embalagem: Confeccionou-se um checklist de embalagem baseado em informações fornecidas pelo site da Agencia Nacional de Vigilância Sanitária a fim de conhecer quais são as informações básicas, obrigatórias e opcionais são inseridas nas embalagens primária (frasco) e secundária (cartucho. Com este checklist verificamos que são componentes obrigatórios da embalagem primária: nome, marca, lote e data de validade. Informações sobre conteúdo, país de origem, fabricante e etc., devem estar contidas na embalagem secundária, e outros itens como modo de uso (quando necessário) podem estar em ambas.

Analise de Concorrentes: O critério para a escolha dos concorrentes foi a inspiração, na fragrância ou na embalagem, no estilo/movimento art déco. Foram selecionados sete concorrentes para análise de informações e aspectos importantes, para compor os requisitos e parâmetros do projeto. (Quadro 1) Foram analisados: o tipo de fragrância, o preço em reais, quantidade em mililitros, inspiração, dispositivo de saída do perfume, material da embalagem, 
acabamento e publico alvo.

Quadro 1 - Concorrentes

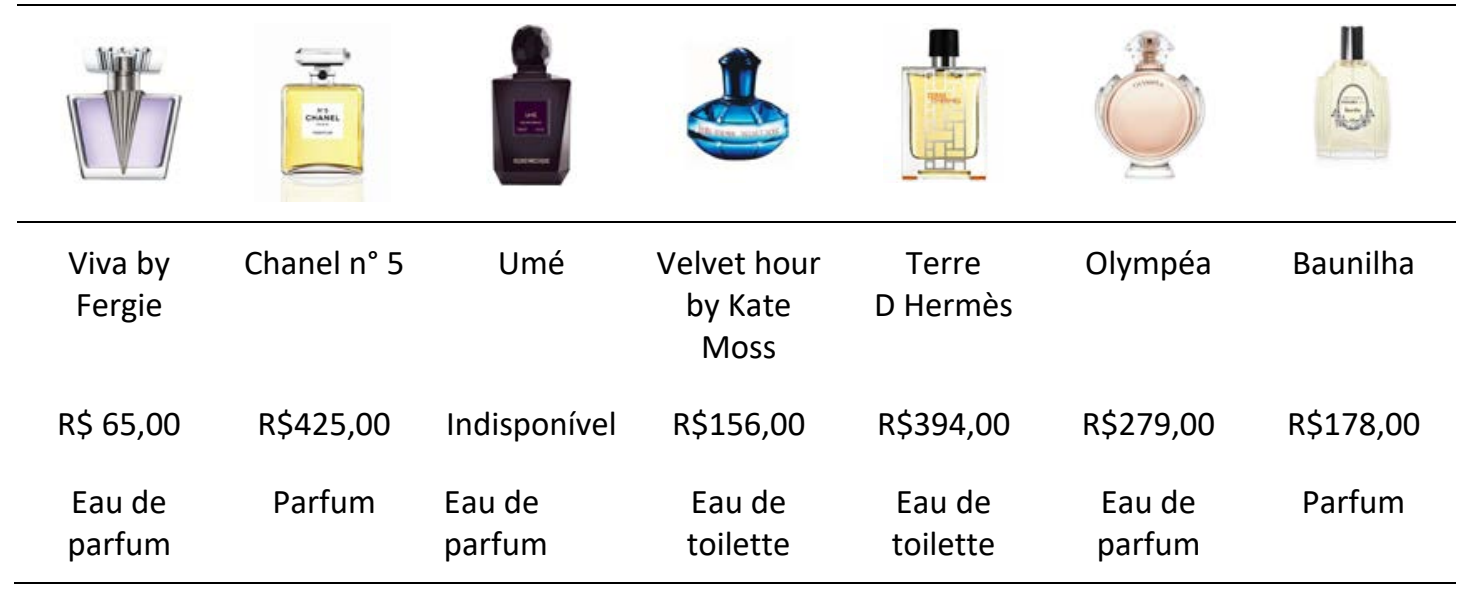

Fonte: Santos (2017)

Entre os concorrentes, apenas o "Baunilha" é nacional. Os tipos de perfume identificados nos concorrentes são: Parfum (maior quantidade de óleos essenciais), Eau de parfum (segundo maior em concentração de óleos) e Eau de toilette. Os preços variaram entre $R \$ 65,00$ e $R \$ 425,00$, a disparidade entre os preços se deve aos tipos de perfume. Com exceção do "Terre D Hermès", todos são destinados ao público feminino. Quanto as embalagens, todas são em vidro com polímero, a maioria possui acabamento transparente e translucido com detalhes metálicos, sendo o "Velvet by Kate Moss" e "Umé" os únicos a possuir cor, e o "Umé" o único com acabamento fosco. Todos possuem o dispositivo de saída do tipo spray. O "Umé" é o único que possui a fragrância inspirada no art decó os demais possuem só as embalagens inspiradas nesse estilo.

Analise Morfológica de elementos arquitetônicos de Rio Tinto: foi confeccionada uma série de painéis visuais buscando analisar os principais elementos arquitetônicos da cidade de Rio Tinto, objetivando identificar elementos que pudessem servir de inspiração para configuração estética do produto. Concordamos com Löbach (2001, p. 162) no que diz respeito a seleção dos elementos configurativos, sendo estes de suma importância, por serem portadores da informação estética do produto eles determinarão as reações que o futuro usuário terá diante do produto. Utilizamos o estudo de Campos (2015) sobre painéis visuais, que propõe painéis imagéticos construídos e modificados durante toda pesquisa.

A Figura 2 apresenta o painel de imersão na cidade de Rio Tinto, é composto por fotografias e palavras chave que remetem à cidade e ao art déco. Nele estão as principais edificações de Rio Tinto como: Cineteatro Orion, igreja de Santa Rita de Cássia, viação Rio Tinto (antigo armazém), palacete Lundgren, delegacia e ainda elementos marcantes construídos em tijolo aparente com a marca da Olaria Rio Tinto. 
Figura 2 - Painel de imersão da cidade de Rio Tinto
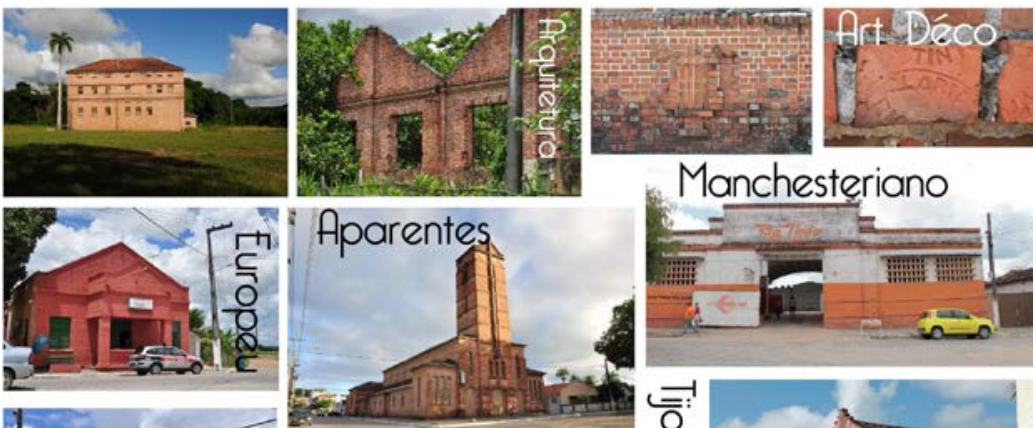

Manchesteriano
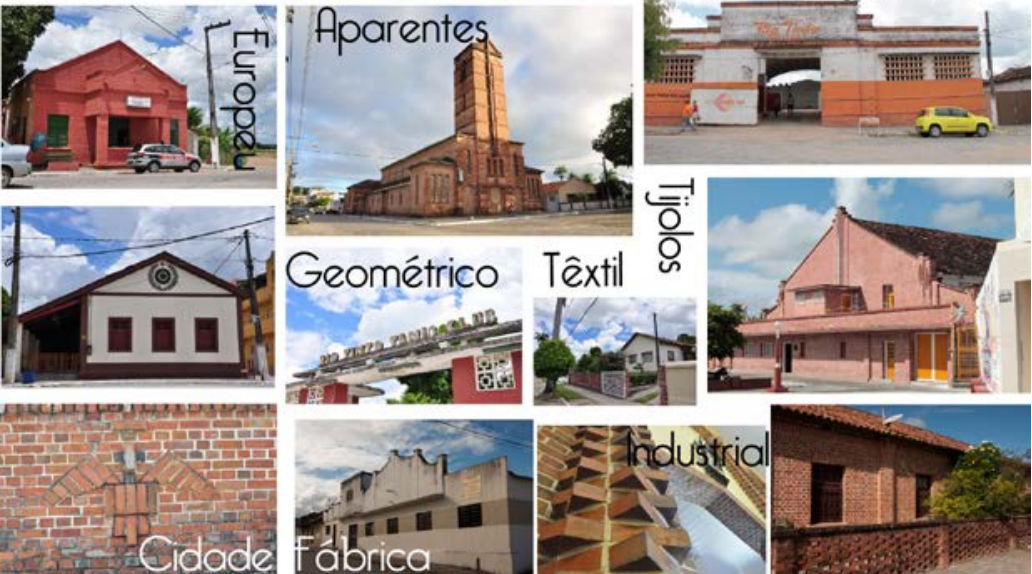

Fonte: Composição de Santos (2017). Acervo: Laboratório de Fotografia/DDesign/UFPB

A Figura 3 apresenta o painel com detalhes dessas principais edificações. Após analisarmos as formas, linhas e textura das edificações por meio dos painéis foi possível identificar formas geométricas, planos paralelos, simetria de forma, escalonamento de fachadas, colunas e capiteis, elementos decorativos em alto relevo, repetição de formas geométricas em diferentes planos, e a textura predominante de tijolo.

Figura 3 - Painel de detalhes das principais edificações

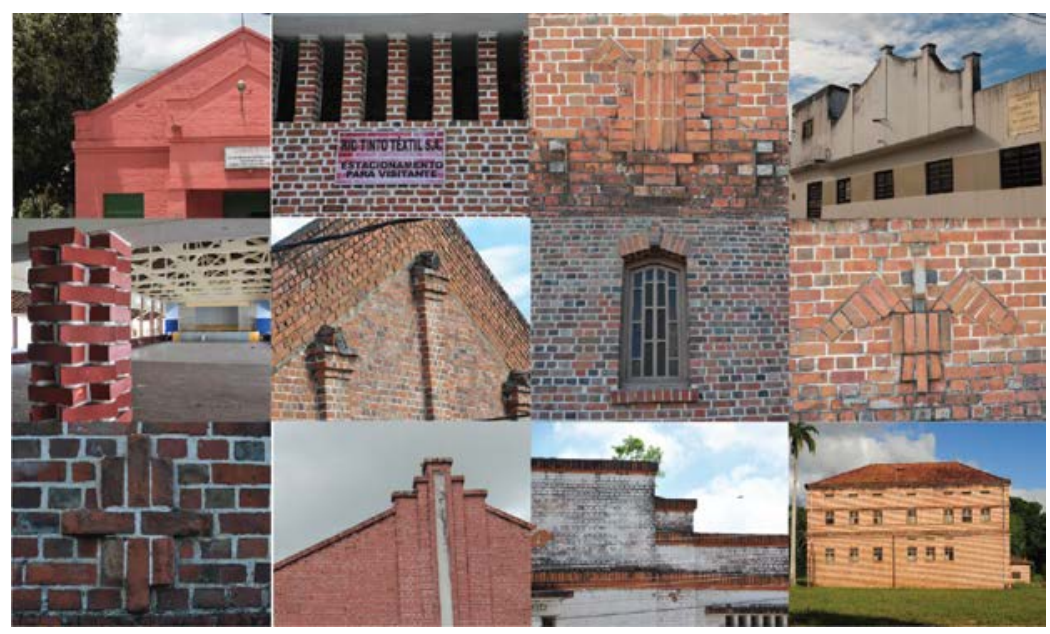

Fonte: Composição de Santos (2017). Acervo: Laboratório de Fotografia/DDesign/UFPB

Analise do Público alvo: Foi elaborada outra série de painéis visuais, buscando conhecer quem é esse público, quais produtos são consumidos por ele e quais lugares o mesmo frequenta. Novamente foram inseridas palavras chave nos painéis e foram usadas fotografias de produtos, de mulheres, e de ícones do art déco como Carmem Miranda, Josephine Barker, J. Carlos, 
transatlântico Normandie, filme Metrópoles e etc. A Figura 4 apresenta a síntese dos três painéis do publico elaborados durante o desenvolvimento do projeto.

Figura 4 - Síntese dos painéis do público alvo

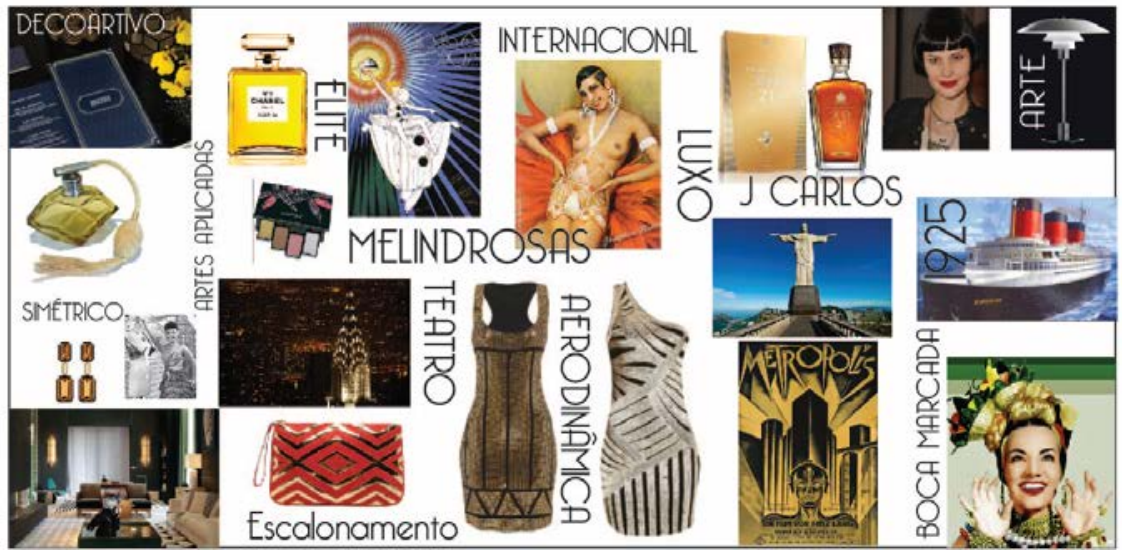

Fonte: Santos (2017)

Sobre a cor Löbach (2000, p.164) afirma tratar-se de "um elemento essencial da figura". A cor é usada para atingir a psique do usuário, ela se relaciona diretamente com ele e é capaz de despertar interesse. Tomando os painéis visuais como base foi desenvolvida uma paleta de cores para utilizar no projeto. Extraímos cores dominantes nos painéis visuais. A Figura 5 apresenta a paleta de cores, dividida em tons terrosos/metálicos, que lembram muito tonalidades de tijolos, além de dourados, e tons neutros.

Figura 5 - Paleta de cores do projeto.

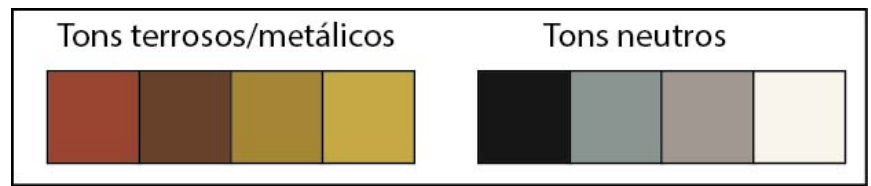

Fonte: Santos (2017)

\subsubsection{Conceitos}

A partir da definição do conceito que deveria solucionar o problema apresentado "Especificamente, o projeto conceitual deve mostrar como a nova embalagem será criada e produzida para atingir a meta da problemática do projeto." (MERINO et al, 2008, p. 9). Nesta etapa foi utilizada a ferramenta brainstorming para a geração de conceitos, criados a partir dos elementos apresentados nos painéis visuais, estes elaborados a partir da ferramenta Atlas. Foram gerados seis conceitos, com os quais foram desenvolvidas alternativas com maior refinamento, todos os conceito e alternativas estão apresentados na figura 6 . Realizamos um estudo de materiais a serem utilizados, devido às características de conservação e o efeito visual, o vidro seria o material mais indicado para o frasco. Para a tampa pensou-se num polímero, devido à praticidade e resistência. 
Figura 6- Geração de conceito e alternativas

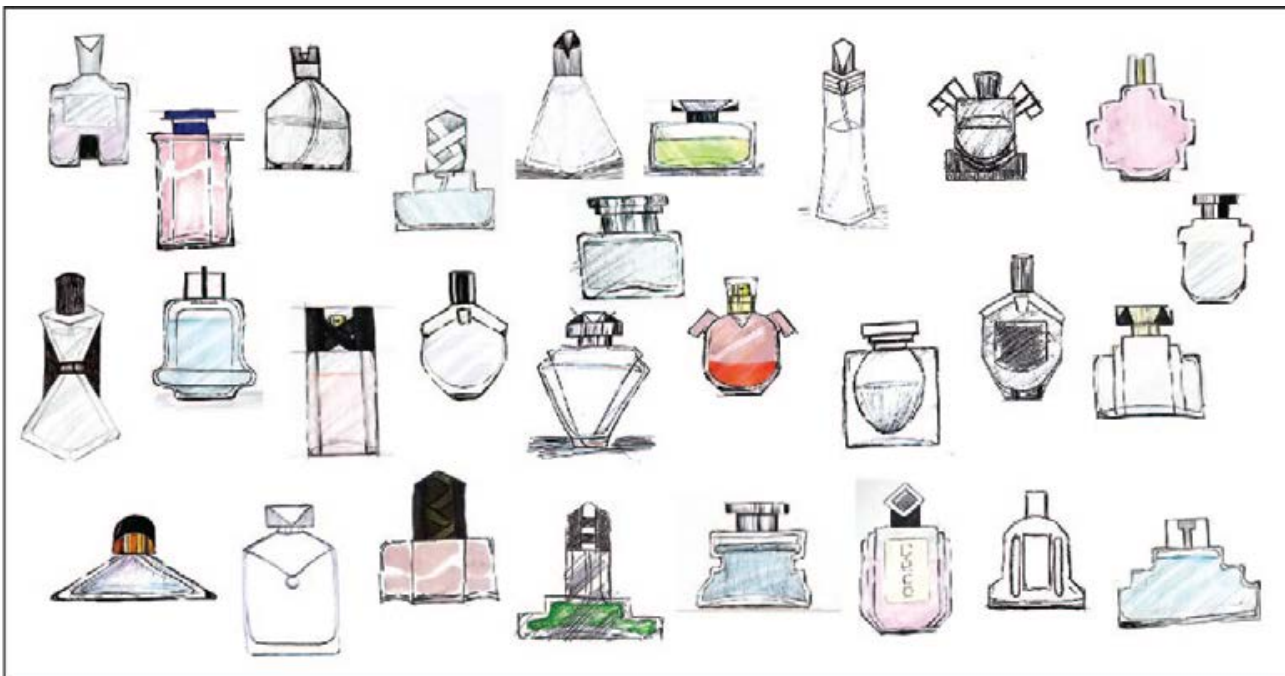

Fonte: Santos (2017)

Matriz avaliativa: Os conceitos e suas respectivas alternativas foram avaliados; sendo os conceitos avaliados como um todo haja vista que a partir deles poderiam ser criadas mais alternativas. Os critérios utilizados foram relacionados com os requisitos do projeto, para que a solução escolhida estivesse de acordo com o que se almeja. Para a atividade de avaliação foram convidados dois profissionais, um designer gráfico e um mestre em design, que interagiram com a primeira autora da pesquisa. Antes da avaliação realizou-se uma breve apresentação de imersão ao tema com todos os painéis. Os critérios da avalição foram: coerência com o usuário, custo de produção, inovação, características art déco e referências a Rio Tinto. Conforme a matriz avaliativa o conceito armazém se mostrou superior, apesar de os demais terem obtido pontuações próximas. A Figura 7 apresenta as alternativas do conceito armazém, e o conceito a ser detalhado encontra-se destacado.

Figura 7 - Alternativas do conceito armazém

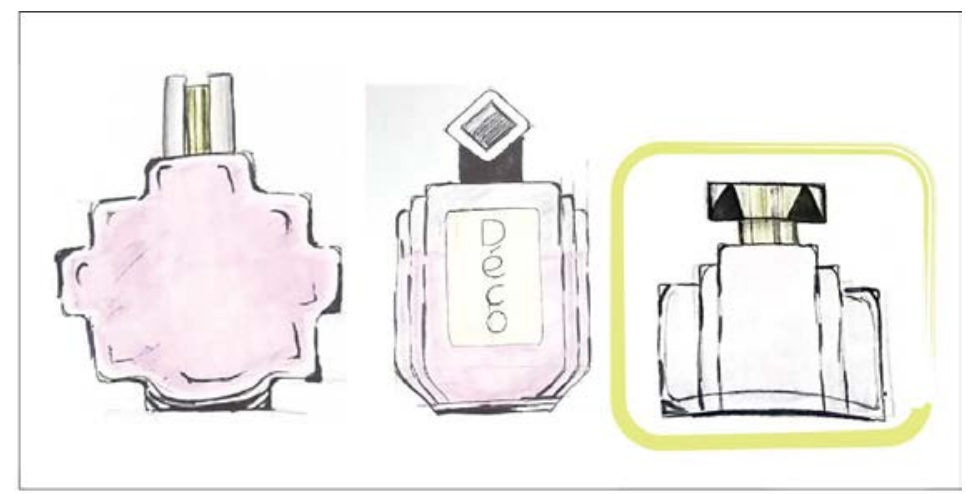

Fonte: Santos (2017)

Após refinamentos, foram confeccionados alguns mockups em isopor para estudos volumétricos, após ajustes e alterações realizadas nos mockups, iniciou-se a modelagem tridimensional digital no software Rhinoceros ${ }^{\circledR} \operatorname{com}_{0}$ qual também foi executado o desenho 
técnico. O software utilizado na renderização foi o $\operatorname{Keyshot}^{\circledR}$, e o resultado é apresentado na Figura 8, efetuou-se um estudo de cores e aplicou-se a paleta cores a tampa (Figura 9). Foi realizado um brainstorming para escolha do nome do perfume, que ficou denominado como "Parfum Rio Tinto", nome simples, contudo forte.

Figura 8 - Redering da modelagem tridimensional digital da embalagem

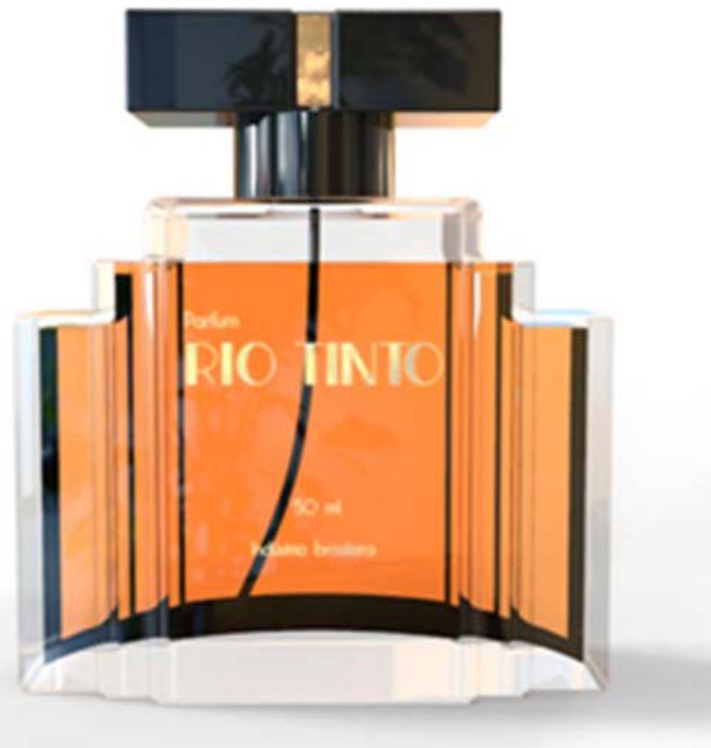

Fonte: Santos (2017)

Figura 9 - Variações de cores

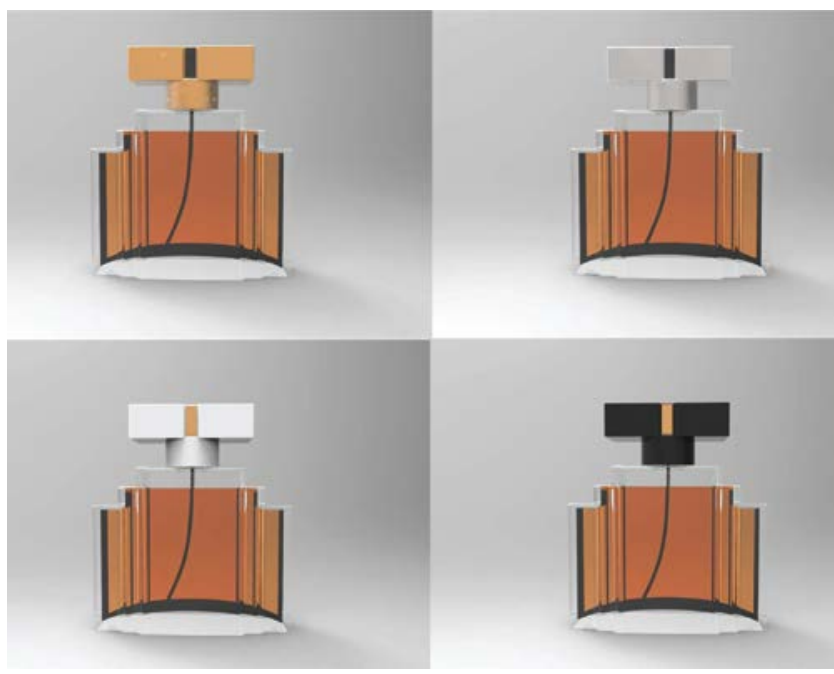

Fonte: Santos (2017)

Foi desenvolvida a embalagem secundária para acondicionar o frasco seguindo os conceitos da empresa Granado/Phebo, utilizando a paleta de cores desenvolvida no projeto. A Figura 10 mostra a planificação da embalagem secundária. 
Figura 10 - Planificação da embalagem secundária do Parfum Rio Tinto

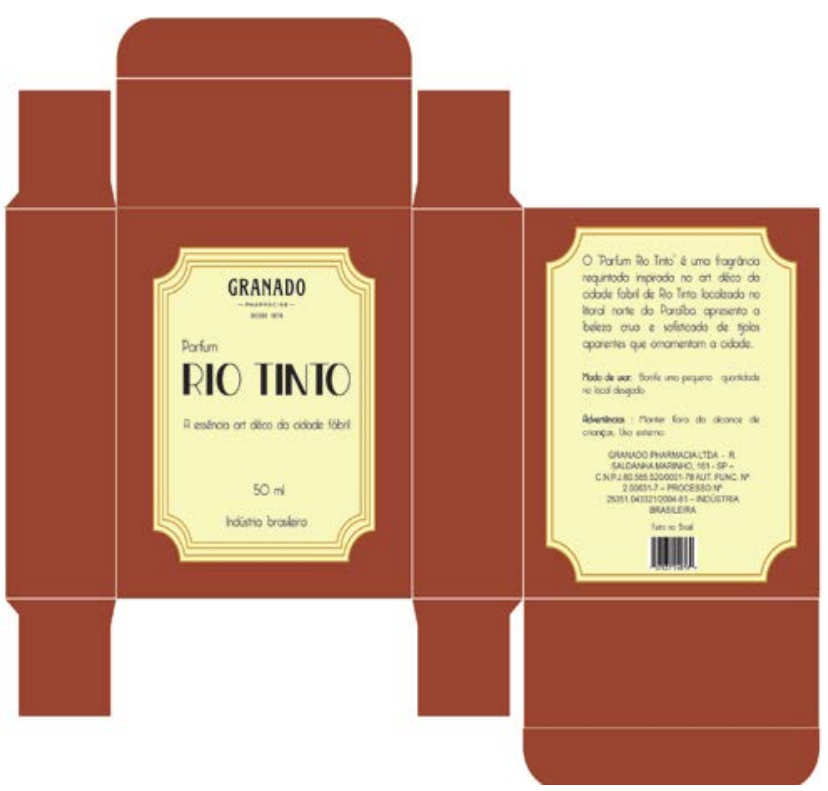

Fonte: Santos (2017)

A confecção do modelo se deu em duas partes, uma referente ao frasco e a outra a tampa do frasco. Iniciou-se com a impressão tridimensional em polímero $A B S$ da tampa e do frasco (utilizado para produzir a matriz) ambos foram lixados até se obter a textura lisa. A matriz do frasco foi produzida em silicone, para a sua confeç̧ão foi utilizado uma caixa e a impressão que serviu de macho para produzir a cavidade. Com a matriz de silicone pronta, foi inserida a resina acrílica transparente, se optou por esse material por se assemelhar ao vidro, com o modelo em resina pronto foram dados acabamentos com diversas lixas e foi aplicado verniz transparente brilhoso. Um esquema simplificado do processo de fabricação se encontra na Figura 11.

Figura 11 - Esquema simplificado da confecção do modelo físico tridimensional

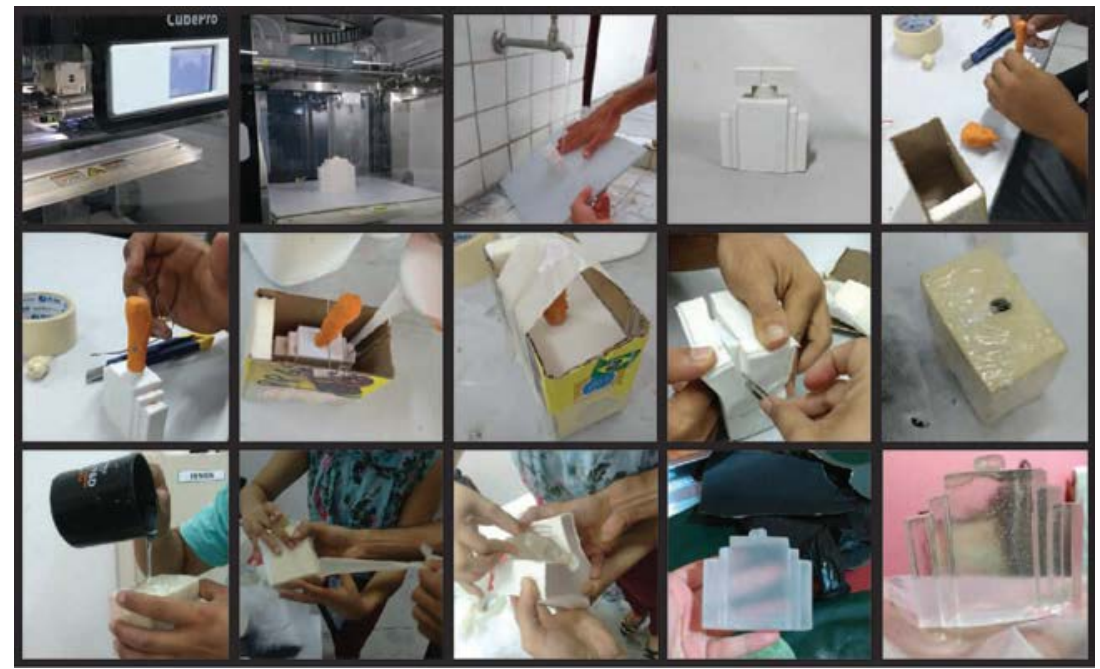

Fonte: Santos (2017) 
No Processo de confeç̧ão da tampa foi utilizada impressão digital 3D, lixamento e tingimento, apresentado na Figura 12. O resultado final do modelo físico está exibido na Figura 13.

Figura 12- Esquema da confecção da tampa.

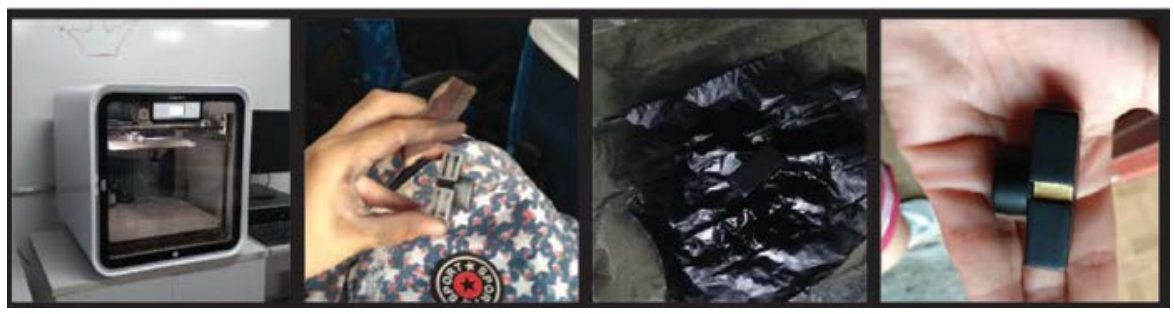

Fonte: Santos (2017)

Figura 13 - Modelo Físico Final.

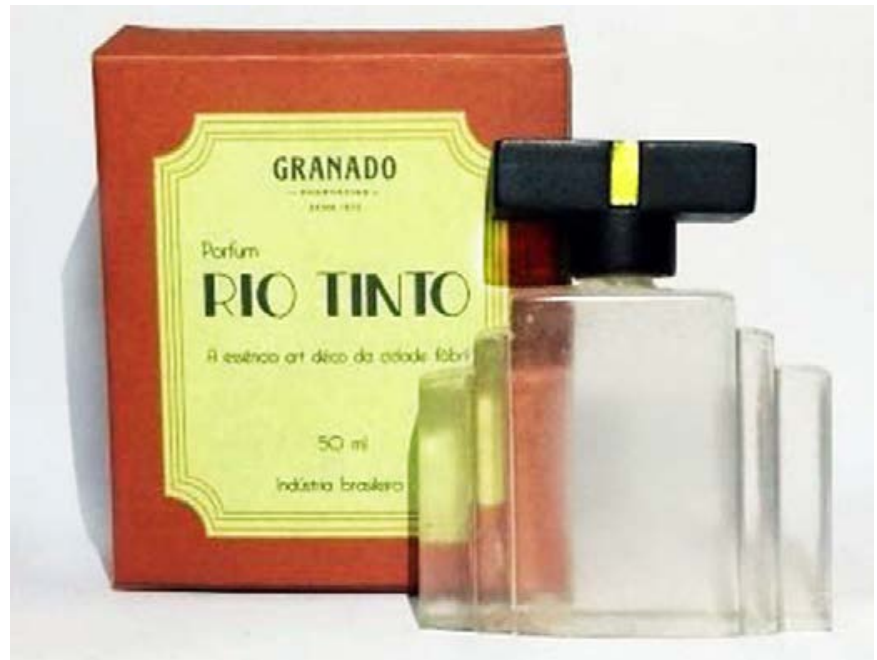

Fonte: Santos (2017)

\section{Conclusões}

O trabalho descrito neste artigo teve como objetivo principal projetar uma embalagem para perfume que contivesse referência nas características art déco presentes na cidade-fábrica de Rio Tinto. O desenvolvimento do produto foi possível graças ao referencial teórico e as análises realizadas e, por meio deles, se pode conhecer o movimento/estilo art déco e a cidade de Rio Tinto, objetos principais desse estudo. É importante ressaltar que, a realização deste projeto teve o intuito de salientar as características arquitetônicas, histórias e o art déco presente na cidade de Rio Tinto.

Durante o desenvolvimento, a alimentação dos painéis visuais e do referencial teórico foi muito importante para aprofundar o conhecimento sobre os assuntos abordados. $\mathrm{O}$ acesso a tecnologias como impressora 3D, disponível no Laboratório de Projetos do Departamento de Design da UFPB, foram de grande valia durante a execução do modelo físico. O banco de fotografias disponibilizado pelo Laboratório de Fotografia do Departamento de Design da UFPB, foi de fundamental importância por fornecer as imagens com qualidade profissional da cidade de Rio Tinto, utilizadas em todo o trabalho. O uso de uma empresa alvo fictícia foi bastante 
importante, pois os conceitos e o publico da empresa possibilitaram refinamentos nas definições do trabalho.

Os resultados obtidos foram satisfatórios, alcançando-se os objetivos a que se tinha proposto, atendendo às indicações do briefing e às especificações dos requisitos e parâmetros do projeto, sendo o produto final passível de produção e comercialização, podendo ser desenvolvida ampla linha de embalagens baseada no mesmo conceito.

Neste sentido, sugere-se o desenvolvimento da fragrância "Parfum Rio Tinto", que traduza para a linguagem olfativa essa cidade ímpar. Por fim, espera-se que esse trabalho incentive a pesquisa local, a valorização do patrimônio cultural e material de Rio Tinto.

\section{Referências}

ABIHPEC. Panorama do setor de HPPC 2016. Disponível em < https://www.abihpec.org.br/novo/wp-content/uploads/2016-PANORAMA-DO-SETORPORTUGU\%C3\%8AS-14jun2016.pdf> Acesso em 17 fev. $2017 \cdot$.

CENTRO BRASIL DESIGN. Diagnóstico do Design Brasileiro. CBD, MDIC. APEX, 2014.

COELHO, Nuno. O Design de Embalagem em Portugal no Século XX - Do funcional ao simbólico O estudo de caso da Saboaria e Perfumaria Confiança, IV colóquio de Doutorados/as do CES, 6-7 dezembro de 2013, Cabo dos Trabalhos.

CORREIA, Telma de Barros. Art Déco e Indústria Brasil, nas décadas de 1930 e 1940 . Anais do Museu Paulista: São Paulo, 2008.

CORREIA, Telma de Barros. Art déco e indústria: Brasil, décadas de 1930 e 1940. Anais do Museu Paulista: História e Cultura Material, v. 16, n. 2, p. 47-104, 2008.

DEMPSEY, Amy. Estilos, escolas e movimentos: Guia enciclopédico de arte moderna. São Paulo, Cosac Naify, 2010.

FORBES BRASIL. Brasil tem o maior mercado de perfumes do mundo. 2014. Disponível em: <http://novo.more.ufsc.br/homepage/inserir_homepage>. Acesso em: 20 fev. 2017.

FORTY, Adrian. Objeto de desejo- Design e sociedade desde 1750. São Paulo: Cosac Naify, 2007.

HARDMAN, Francisco Foot. Nem pátria, nem patrão! Memória operária, cultura e literatura no Brasil. SciELO-Editora UNESP, 2003.

KOTLER, Philip. ARMSTORNG, Garry. Princípios de Marketing. Rio de Janeiro: Prentice/Hall do Brasil, 1993.

LEHMKUHL, Luciene; DA SILVA, Jeferson Luiz Braz. A cidade-fábrica de rio tinto na pesquisa em design. Blucher Design Proceedings, v. 2, n. 9, p. 437-448, 2016.

LÖBACH, Bernd. Design industrial. São Paulo: Edgard Blücher, 2001.

MERINO, Eugenio; MERINO, Giselle; CARVALHO, Luiz Roberto. Guia de Orientação para o Desenvolvimento de Embalagem: uma Proposta de Sistematização Orientavas. Revista D.: Design, Educação, Sociedade e Sustentabilidade., v. 2, n. 1, p. 84-100, 2009.

MESTRINER, Fábio. Design de Embalagem: Curso Básico. 2. ed. São Paulo: Pearson Makronbooks, 
2002.

NEGRÃO, Celso. CAMARGO, Eleida. Design de embalagem: do Marketing à produção. Novatec Editora, 2008.

PANET, Amélia. MELO. José Octavio de A. PANET, Miriam. GUNN, Philip. CORREIA, Telma de B. Rio Tinto: Estrutura urbana, trabalho e cotidiano. João Pessoa: UNIPÊ Editora, 2002.

ROITER, Márcio Alves. Pindorama modernista: influência indígena no art déco brasileiro. Culturas indígenas. Brasília: Ministério das Relações Exteriores, 2012, p.74-89.

ROITER, Márcio Alves et al. Art déco Coleção Berardo: What a Wonderful wolrd. Calheta, Eurodois, 2011.

SANTOS, Juciely Targino dos. Embalagem para perfume com aspectos art déco da arquitetura de Rio Tinto. 2017. 140 f. TCC (Graduação) - Curso de Design, Departamento de Design, Universidade Federal da Paraíba, Rio Tinto, 2017. 